\title{
The fluorescence analysis of laser photolysis of phenols in water
}

\author{
O. Tchaikovskaya, ${ }^{1, \dagger}$ I. Sokolova, ${ }^{1}$ O. Bazyl, ${ }^{1}$ V. Swetlichnyi, ${ }^{1,2}$ \\ T. Kopylova, ${ }^{1}$ G. Mayer, ${ }^{2}$ and N. Sultimova ${ }^{2}$ \\ ${ }^{1}$ Siberian Physical Technical Institute, 1, Novo-Sobornaia sq., 634050, Tomsk, Russia \\ ${ }^{2}$ Tomsk State University, 36, Lenin av, 634050, Tomsk, Russia
}

\begin{abstract}
Photolysis of phenol and $p$-chlorophenol exposed to $\mathrm{KrCl}$ - and Nd-YAG laser light is studied by electron spectroscopy and fluorescence and quantum chemical techniques. The decrease of the quantum yield of phenol fluorescence with increase in the excitation energy is not related to dynamic changes in the intramolecular photophysical processes; rather this is a result of increased photoreaction efficiency. Chlorine substitution for para-state of phenol is shown to strengthen the OH-bond in excitation into the long wavelength absorption band.
\end{abstract}

\section{INTRODUCTION}

Tomsk oblast' is part of the West-Siberian region of Russia. All this territory is famous for vast resources of coal, oil, and gas. There is a large number of coal- and petroleum-processing and transportation complexes in this area. Consequently, waste water is severely contaminated with xenobiotics. The most hazardous of these is phenol and its derivatives [1]. Water chlorination as a means of its disinfection is most widely used in practice, even though it gives rise to the formation of chlorine phenols of varying composition. Their biological action is more dangerous than phenol itself [2-4]. A large number of papers devoted to this problem and its solution are available in the relevant literature [5-7]. The use of UV radiation of varying power is one of the modern techniques for water purification from organic molecular contamination [8]. This is a nonreactive and ecologically safe technique. The complex character of phototransformations occurring under UV irradiation of aqueous media containing impurities generates an urgent need for fundamental studies of this phenomenon. Using lasers significantly extends the possibilities of studying phototransformation mechanisms and photolysis control as compared with conventional lamp sources [9]. This makes them a promising tool for investigating photoprocesses in molecules. The narrow spectral range of laser radiation produces a selective effect on individual molecular electron states. The low laser-beam divergence allows laser light to be transported with a minimum loss to any point of interest and the energy deposited in the solution to be determined. An increase in the power density of exciting radiation in a narrow spectral range may cause nonlinear laser-matter interactions [10].

\footnotetext{
†E-mail: tchon@phys.tsu.ru
}

The purpose of the work is a fundamental study of the photochemical properties of phenol and $p$-chloro-phenol solutions in water under UV irradiation from different sources. Photolysis of phenols was studied using a comprehensive approach. Schemes of electronic excitation states of phenols under study, rate constants of internal conversion and intersystem crossing conversion were calculated, and the photochemical molecular properties were predicted using quantumchemical methods. The spectral luminescent characteristics of phenols under excitation were examined by electron spectroscopy and fluorescence. Further, the effects of the wavelength and excitation power on phototransformations of phenols in water were studied using different excitation sources ( $\mathrm{KrCl}$ and $\mathrm{Nd}-\mathrm{YAG}$ lasers). The changes of the spectral luminescent properties were controlled both during irradiation (from laser-induced fluorescence spectra-LIF) [11] and after the exposure (from steady-state absorption and fluorescence spectra). The findings of the investigations are presented in this work.

\section{EXPERIMENTAL TECHNIQUE}

We studied photolysis of aqueous phenol and $p$ chlorophenol solutions of $5 \cdot 10^{-4}-8 \cdot 10^{-3} \mathrm{~mol} \cdot \mathrm{L}^{-1}$ concentration. The technical data on the excitation sources used are listed in Table 1. The absorption and fluorescence spectra were recorded by a conventional procedure using a Specord M40 spectrophotometer and a Hitachi M850 spectrofluriometer. The experimental setup for photolysis and registration of the LIF spectra excited by the fourth harmonic Nd-YAG laser ladiation is given in detail in [11]. On excitation by a KrCl-laser the beam was focused by crossing long-focus cylindrical lenses. This provides power densities up to $30 \mathrm{MW} / \mathrm{cm}^{2}$. In all cases the same amount of energy $\left(1-1.2 \mathrm{~J} / \mathrm{cm}^{3}\right)$ was absorbed. 


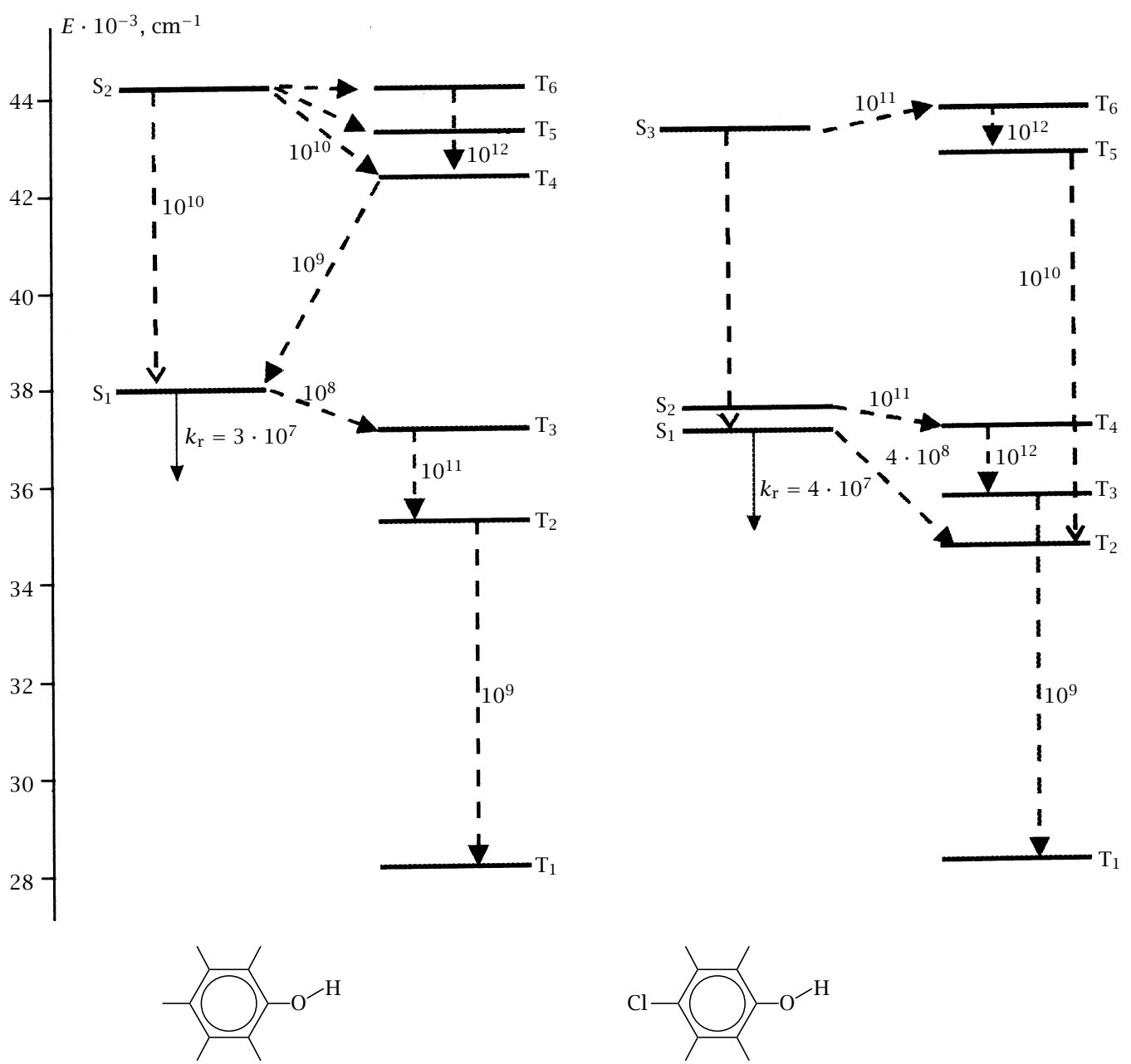

Figure 1. Energy diagram of electronically exited states and rate constants of radiationless processes $\left(s^{-1}\right)$ in phenol and $p$-chlorophenol molecules ( $K_{\mathrm{r}}$-the radiation rate constant).

Quantum-chemical calculations for phenol molecules were performed by the INDO parametrization method [12]. The quantum-chemical calculation procedure is described elsewhere [13]. Since the chemical bonding breaking process affects a molecule skeleton (and $\sigma$-electrons forming the skeleton) the bond breaking due to phototransformation largely occurs in states of the $\pi \sigma^{*}-, \sigma \pi^{*_{-}}$, and $\sigma \sigma^{*}$-type. The probability of the photoreaction is determined both by the degree of localization of the energy absorbed by the molecule on the ruptured bond, and by the decrease of the bond strength in the photodissociative state. Electron transitions of the $\pi \sigma^{*}$ - and $\sigma \pi^{*}$-type are known to be weakly allowed. Therefore direct population of photodissociative states of this type is of low efficiency. In the absence of direct excitation of the photodissociative state it can be populated by intramolecular photophysical relaxation processes of the absorbed energy or by multiple-stage absorption.

\section{RESULTS AND DISCUSSION}

3.1. Calculation results. An analysis of our quantum-chemical calculations shows that the electronic-excitation states of phenol where we can expect the rupture of the $\mathrm{OH}\left(\mathrm{S}\left(\pi \sigma^{*}{ }_{\mathrm{OH}}\right)\right.$ and $\left.\mathrm{T}\left(\pi \sigma^{*} \mathrm{O}-\mathrm{H}\right)\right)$ bonds lie around $50000 \mathrm{~cm}^{1}$ (Figure 1). The bond strength in these states decreases drastically and their potential curves correspond to the bond rupture [14]. One of the conditions for chemical bond rupture in the electron excitation states is the decrease of bond strength under electron excitation into a state localized on the ruptured bond. In terms of the quantum-chemical calculations the population of the bond corresponds to its strength. The results given in Table 1 show that the strongest depopulation occurs in the $\mathrm{S}\left(\pi \sigma^{*}{ }_{\mathrm{O}-\mathrm{H}}\right)$ and $\mathrm{T}\left(\pi \sigma^{*}{ }_{\mathrm{O}-\mathrm{H}}\right)$ states. An analysis of the photolytical rate constants shows that the photodissociative $\mathrm{T}\left(\pi \sigma^{*}{ }_{\mathrm{O}-\mathrm{H}}\right)$ state is populated more 
Table 1. Technical data on excitation sources.

\begin{tabular}{ccccc}
\hline \multirow{2}{*}{ Excitation source } & Wavelength, nm & $\begin{array}{c}\text { Pulse repetition rate, } \\
\mathrm{Hz} / \text { pulse duration, } \mathrm{nm},\end{array}$ & $\begin{array}{c}\text { Peak power } \\
\text { density, } \mathrm{MW} / \mathrm{cm}^{2}\end{array}$ \\
\cline { 2 - 4 } $\begin{array}{c}\text { Fourth harmonic output } \\
\text { of a Nd-YAG laser }\end{array}$ & 266 & $3 \cdot 10^{3} / 200$ & $\leq 10^{-3}$ & $\begin{array}{l}\text { Photolysis, spectral } \\
\text { luminescent properties of } \\
\text { irradiated solutions, spectra } \\
\text { and intensity of laser-induced } \\
\text { fluorescence }\end{array}$ \\
\hline KrCl laser & 222 & $1 / 7$ & $1 \div 30$ & \\
\hline
\end{tabular}

efficiently. In doing so, its probability increases with exciting quantum energy. Thus, the $\mathrm{OH}$-bond breaking in phenol due to phototransformation is increased when excited in the center region of the absorption spectrum.

An analysis of the nature of molecular orbitals (MO) of $p$-chlorophenol and their comparison with those of phenol shows that atomic orbitals (AO) of chlorine take part in the formation of the upper populated $\pi$-MO. This results in singlet and triplet states of the $\pi \sigma^{*}$ type in the $p$-chlorophenol absorption spectrum. In this case, the $\sigma^{*}$-orbital is partially localized on the $\mathrm{C}-\mathrm{Cl}$ bond $\left(\mathrm{S}_{2}\right.$ and $\mathrm{T}_{2}$ states, Figure 1$)$. The singlettriplet conversion rate constant in the $p$-chlorophenol molecule is increased. Unlike phenol, the conversion is the basic deactivation channel for the fluorescent state [15]. As a result, the efficiency of the excited molecules leaving for the triplet state channel is increased as the excitation energy is increased. This suggests that the fluorescence quantum yield decreases in the $p$-chlorophenol molecule as the excitation energy is increased even in the absence of transformations. Because of this property, $p$-chlorophenol differs radically from phenol for which this dependence is due to the photolysis alone [14].

\subsection{Phenol and p-chlorophenol photolysis under} exposure to Nd-YAG and $\mathrm{KrCl}$ laser radiation. Let us consider phenol and chlorphenol photolysis under exposure to the fourth harmonic output of a Nd-YAG laser. The laser wavelength at $266 \mathrm{~nm}$ corresponds to the long-wavelength spectral region of the absorption spectra of phenol and $p$-chlorophenol. The absorption spectra of phenol solutions before and after irradiation are shown in Figures 2(a) and 2(b). The most probable decay pathway for phenols exposed to laser light at $266 \mathrm{~nm}$ is transformation from the lower electronic excitation states. Due to low intensity of exciting radiation the polulation of the upper electronic states by reabsorption is unlikely to occur. A detailed analysis of the nature of photoproducts under excitation into lower excited states is performed in [10]. It should be noted that the excitation in the long-wavelength absorption band of $p$-chlorophenol directly excites the $\mathrm{S}_{2}\left(\pi \sigma^{*}\right)$ state, where the $\mathrm{C}-\mathrm{Cl}$ bond is involved, and initiates the
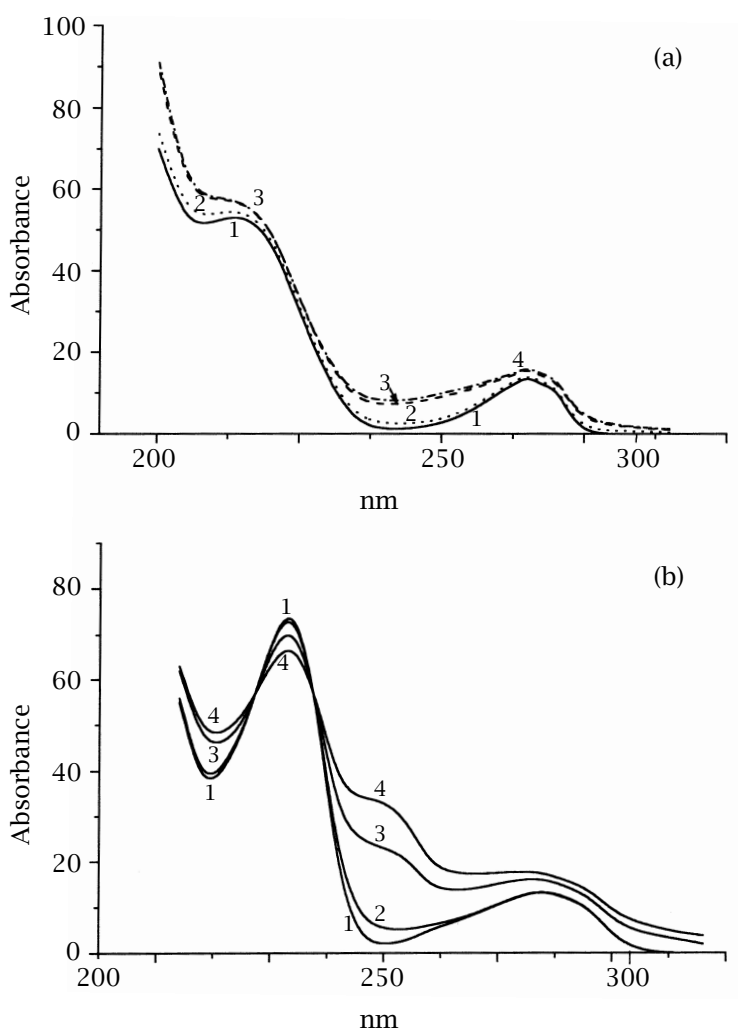

Figure 2. Phenol (a) and p-chlorophenol (b) absorption spectra before (1(a) and 1(b)) and after (2(a) and 2(b)) irradiation by a Nd-YAG laser (power density $\leq 10^{-3} \mathrm{MW} / \mathrm{cm}^{2}$ ) and by a $\mathrm{KrCl}$ laser: power density $30 \mathrm{MW} / \mathrm{cm}^{2}, 3($ a) and 3(b), power density $1 \mathrm{MW} / \mathrm{cm}^{2}$ (4(a) and 4(b)).

$\mathrm{S}_{1}\left(\pi \pi^{*}\right) \rightarrow \mathrm{T}_{2}\left(\pi \sigma^{*}\right)$ conversion process populating a triplet state of the $\pi \sigma^{*}$ - type. Thus, chlorine substitution in a phenol molecule strengthens the $\mathrm{OH}$-bond and decreases the probability of population of photodissociative states related to the $\mathrm{OH}$-bond under excitation in the long-wavelength absorption band, and, to a certain extent, the substitution diminishes the probability of bond rupture due to phototransformation. At the same time, a photoreaction related to the $\mathrm{C}-\mathrm{Cl}$ bond breaking occurs. Due to this fact, the $p$-chlorophenol phototransformation efficiency is much higher than that of 
Table 2. $\mathrm{OH}$ and $\mathrm{CCl}$ bond population of phenol and $p$-chlorophenol in different electronic excitation states.

\begin{tabular}{|c|c|c|c|c|c|c|}
\hline \multirow{3}{*}{ Compound } & \multicolumn{6}{|c|}{ State } \\
\hline & $\mathrm{S}_{0}$ & $\mathrm{~S}_{1}\left(\pi \pi^{*}\right)$ & $\mathrm{S}_{2}\left(\pi \pi^{*}\right)$ & $\mathrm{S}\left(\pi \sigma^{*} \mathrm{OH}\right)$ & $\mathrm{T}_{1}\left(\pi \pi^{*}\right)$ & $\mathrm{T}\left(\pi \sigma^{*} \mathrm{OH}\right)$ \\
\hline & \multicolumn{6}{|c|}{ OH bond } \\
\hline phenol & 0.589 & 0.587 & 0.587 & -0.176 & 0.589 & -0.066 \\
\hline \multirow[t]{2}{*}{$p$-chlorophenol } & 0.585 & 0.585 & 0.584 & 0.140 & 0.585 & -0.009 \\
\hline & \multicolumn{6}{|c|}{ CCl bond } \\
\hline$p$-chlorophenol & $\begin{array}{c}S_{0} \\
0.468\end{array}$ & $\begin{array}{c}\mathrm{S}_{1}\left(\pi \pi^{*}\right) \\
0.490\end{array}$ & $\begin{array}{c}\mathrm{S}_{2}\left(\pi \sigma^{*}\right) \\
-0.403\end{array}$ & $\begin{array}{c}\mathrm{S}_{3}\left(\pi \pi^{*}\right) \\
0.478\end{array}$ & $\begin{array}{c}\mathrm{T}_{1}\left(\pi \pi^{*}\right) \\
0.478\end{array}$ & $\begin{array}{c}\mathrm{T}_{2}\left(\pi \sigma^{*}\right) \\
-0.392\end{array}$ \\
\hline
\end{tabular}

phenol exposed to the fourth harmonic output of a NdYAG laser. In the fluorescence spectrum of the aqueous $p$-chlorophenol solution immediately after irradiation at $\lambda=266 \mathrm{~nm}$, the band peaking at $330 \mathrm{~nm}$ is observed. This band belongs to hydroquinone fluorescence (Figure 3 ) and appears to be due to the $\mathrm{C}-\mathrm{Cl}$ bond rupture resulting from phototransformation.

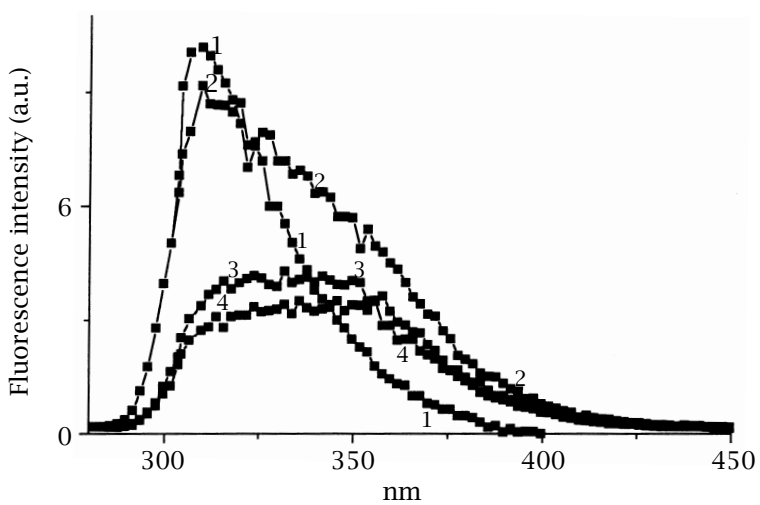

Figure 3. Fluorescence spectra of p-chlorophenol $\left(10^{-3} \mathrm{~mol} \cdot \mathrm{L}^{-1}\right.$ concentration) in water. The solution before stady-state excitatuon (1), laser-induced fluorescence spectra on irradiation by fourth harmonic output of a Nd-YAG laser. Energy deposition: $1.2 \mathrm{~J} / \mathrm{cm}^{3}$ (2), $7.1 \mathrm{~J} / \mathrm{cm}^{3}$ (3), and $25 \mathrm{~J} / \mathrm{cm}^{3}$ (4).

Let us turn to an analysis of the spectral luminescence data on irradiation by an excimer $\mathrm{KrCl}$ laser. The laser wavelength at $222 \mathrm{~nm}\left(45000 \mathrm{~cm}^{-1}\right)$ excites the $\mathrm{S}_{2}$ state of phenol and $\mathrm{S}_{3}$ state of $p$-chlorophenol (Figure 1). The absorption and fluorescence spectra are shown in Figures 4 and 5. For the molecules under study we recorded an increase in the phototransformation efficiency under excitation at $222 \mathrm{~nm}$. Several factors may be responsible for the increased photolytic efficiency. One of these may be the fact that the photoreaction of the OH-bond rupture in phenol and in its chlorinesubstitute under excitation in the long-wavelength and central region of the spectrum occurs by predissociation. The calculations show that the photodissociative states are populated more efficiently when the $S_{2}\left(\pi \pi^{*}\right)$ state of phenol and $S_{3}(\pi \pi *)$ state of $p$-chlorophenol are excited [15].

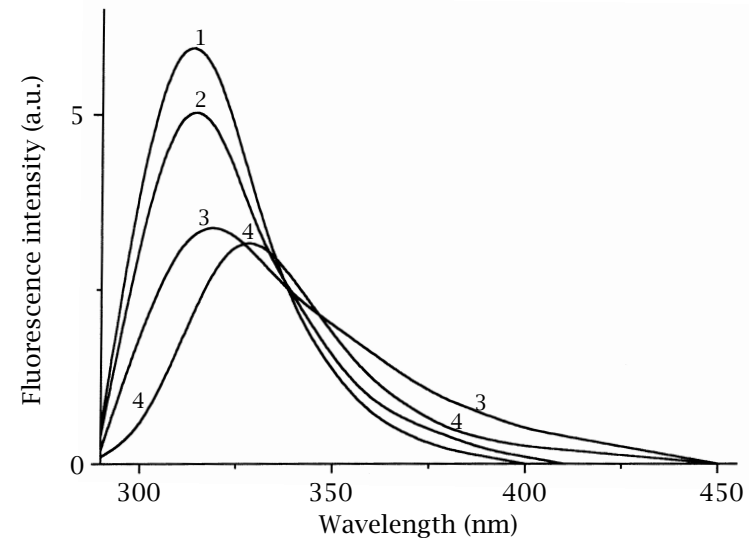

Figure 4. Fluorescence spectra of p-chlorophenol before (1) and after (2 and 3) irradiation by a $\mathrm{KrCl}$ laser and by a $\mathrm{Nd}$ YAG laser (4). Energy deposition: $1.2 \mathrm{~J} / \mathrm{cm}^{3}$ (2), $7.1 \mathrm{~J} / \mathrm{cm}^{3}$ (3 and 4).

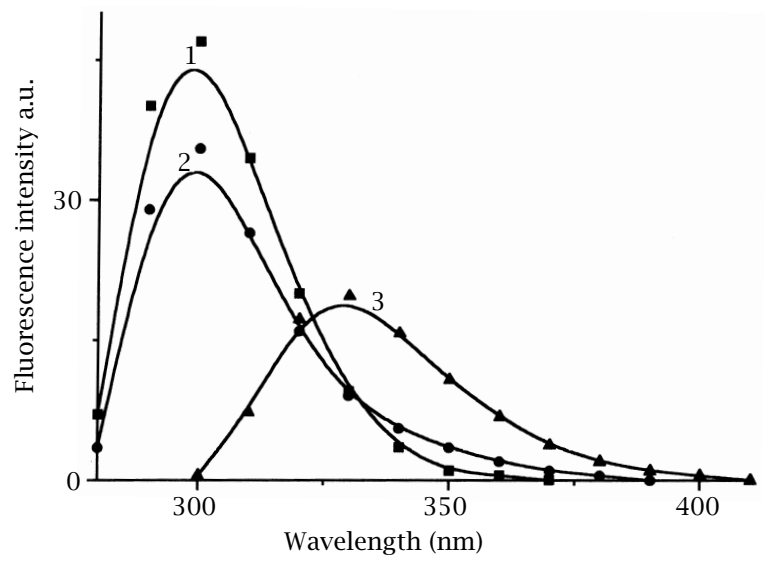

Figure 5. Fluorescence spectra of phenol $\left(10^{-3} \mathrm{~mol} \cdot \mathrm{L}^{-1} \mathrm{con}\right.$ centration) in water (1) and hydroquinone (3) and phenol solution irradiated by a $\mathrm{KrCl}$ laser (energy deposition: $1.2 \mathrm{~J} / \mathrm{cm}^{3}$ ) (2).

This should increase the efficiency of the photoreaction of interest under excitation in the central spectral region. This is what we observed in the experiment. Another reason for the increased photolytic efficiency of phenols under $\mathrm{KrCl}$ laser excitation as compared to 
that of the fourth harmonic output from a Nd-YAG laser may be a further reaction between the solvent radicals formed under the action of high-power UV radiation and unexcited molecules of phenol or $p$-chlorophenol.

Furthermore, phenol and $p$-chlorophenol photolysis in water under the $\mathrm{KrCl}$ laser irradiation was performed at two power densities of 1 and $30 \mathrm{MW} / \mathrm{cm}^{2}$. The phototransformation efficiency for phenol irradiated at 1 and $30 \mathrm{MW} / \mathrm{cm}^{2}$ differs but slightly (Figure 4). For $p$-chlorophenol, the photolysis proceeds more effectively at $1 \mathrm{MW} / \mathrm{cm}^{2}$ than at $30 \mathrm{MW} / \mathrm{cm}^{2}$. This can be attributed to the increase in the concentration of excited molecules and decline in the ground state population as the power density is increased up to $30 \mathrm{MW} / \mathrm{cm}^{2}$. The discussion of the phenol photolysis products is beyond the scope of this paper and is given, for example, in [16-18].

\section{CONCLUSIONS}

The results of experimental studies and quantumchemical calculations suggest the following conclusions on the ways and mechanisms of transformation of phenol in water:

1. A comparison of the LIF and steady-state fluorescence spectra before and after irradiation of the solutions shows that chlorine substitution increases the phototransformation rate.

2. The efficiency of the OH-bond rupture due to phototransformation in phenol and in its chlorine substitute increases under excitation in the central region of the absorption spectrum (222 nm).

3. The probability for the OH-bond rupture due to phototransformation in $p$-chlorophenol decreases under excitation in the long-wavelength region of the absorption band $(266 \mathrm{~nm})$. In this case, the probability of the CCl-bond rupture due to phototransformation increases.

\section{ACKNOWLEDGEMENTS}

The authors are thankful to Prof. Yu. P. Meshalkin for the posibility of performing experiments in his laboratory and to Prof. V. Ya. Artyukhov for providing a software package. The work is supported by the Russian Federation Foundation for Fundamental Research (project 98 Siberia No. 98-03-03059) and by a Grant (project EOO-12.0 235) from RF Ministry of Education.

\section{References}

[1] I. V. Sokolova, Yu. G. Slizhov, P. A. Mizin, O. N. Tchaikovskaya, and M. A.Gavrilenko, Atmos. Oceanic Opt. 13 (2000), 271.

[2] G. Fellenberg, Zagraznenie prirodnoi vody. (Russ.) Mir, Moscow, 1997.

[3] V. V. Goncharuk and N. P. Potapenko, Chemistry and technology of water 20 (1998), 190.

[4] M. B. Arkhipova, L. Ya. Tereshchenko, and Yu. M. Arkhipov, Ecological Chemistry 7 (1998), 229.

[5] K. Oudjehari and R. Boule, J. Photochemistry. Photobiology 62 (1992), 363.

[6] O. Daniel Martire and E. Silvia Braslavsky, J. Photochemistry. Photobiology 61 (1991), 113.

[7] Yu. I. Skurlatov and E. V. Shtamm, Khim. Fizika 16 (1997), 55.

[8] O. Legrini, E. Oliveros, and A. Braun, Chem. Rev. 93 (1993). 671.

[9] V. Yu. Baranov, Yu. A. Kolesnikov, and A. A. Kotov, Kvantovaia Electronika 28 (1999), 95.

[10] V. Swetlichnyi, R. Kuznetsova, T. Kopylova, et al., Atmos. Oceanic Opt. 14 (2001), 271.

[11] V. Swetlichnyi, O. Tchaikovskaya, O. Bazyl', et al., High Energy Chemistry 35 (2001), in print.

[12] V. Ya. Artukhov and A. I. Galeeva, Ivs. Vyzov Fizika (1986), 96.

[13] G. V. Mayer, O. K. Bazyl', V. Ya. Artyukhov, and S. V. Kharitonova, High Energy Chemistry 28 (1994), 259.

[14] O. K. Bazyl', V. Ya. Artyukhov, G. V. Mayer, and I. V. Sokolova, High Energy Chemistry 34 (2000), 30.

[15] O. K. Bazyl', V. Ya. Artyukhov, G. V. Mayer, and I. V. Sokolova, High Energy Chemistry 35 (2001), 33.

[16] O. N. Tchaikovskaya, I. V. Sokolova, and N. B. Sultimova, Proceedings of SPIE. Sixth Intern. Symp. an Atmospheric and Ocean Optics, Vol. 3983, Proc. SPIE, G. G. Matvienko and V. P. Lukin (eds.), 1999, p. 499.

[17] O. Tchaikovskaya, I. Sokolova, R. Kuznetsova, V. Svetlichnii, T. Kopylova, and G. Mayer., J. of Fluorescence 10 (2000), 403.

[18] O. Tchaikovskaya, I. Sokolova, R. Kuznetsova, V. Swetlichnyi, T. Kopylova, and G. Mayer, Luminescence 15 (2000), 114. 


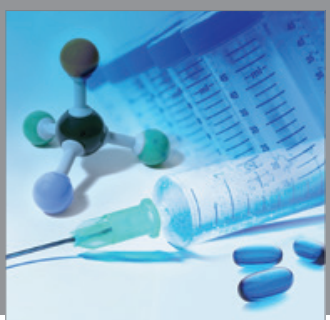

International Journal of

Medicinal Chemistry

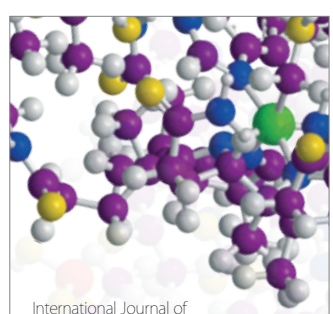

Carbohydrate Chemistry

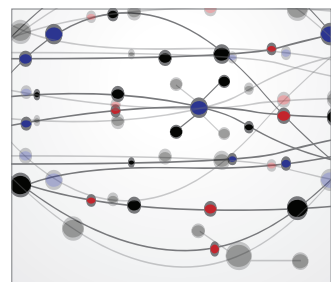

The Scientific World Journal
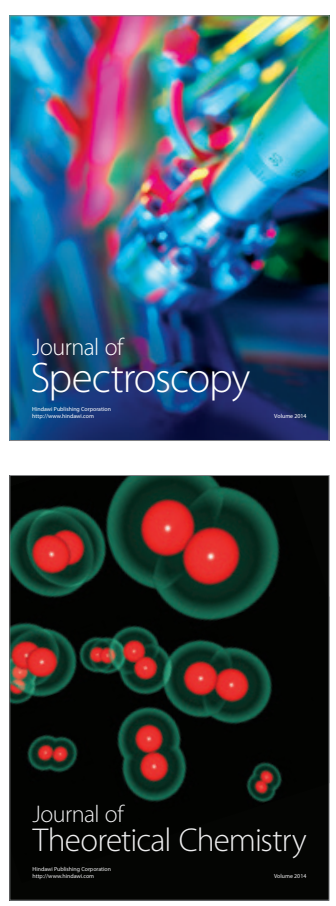
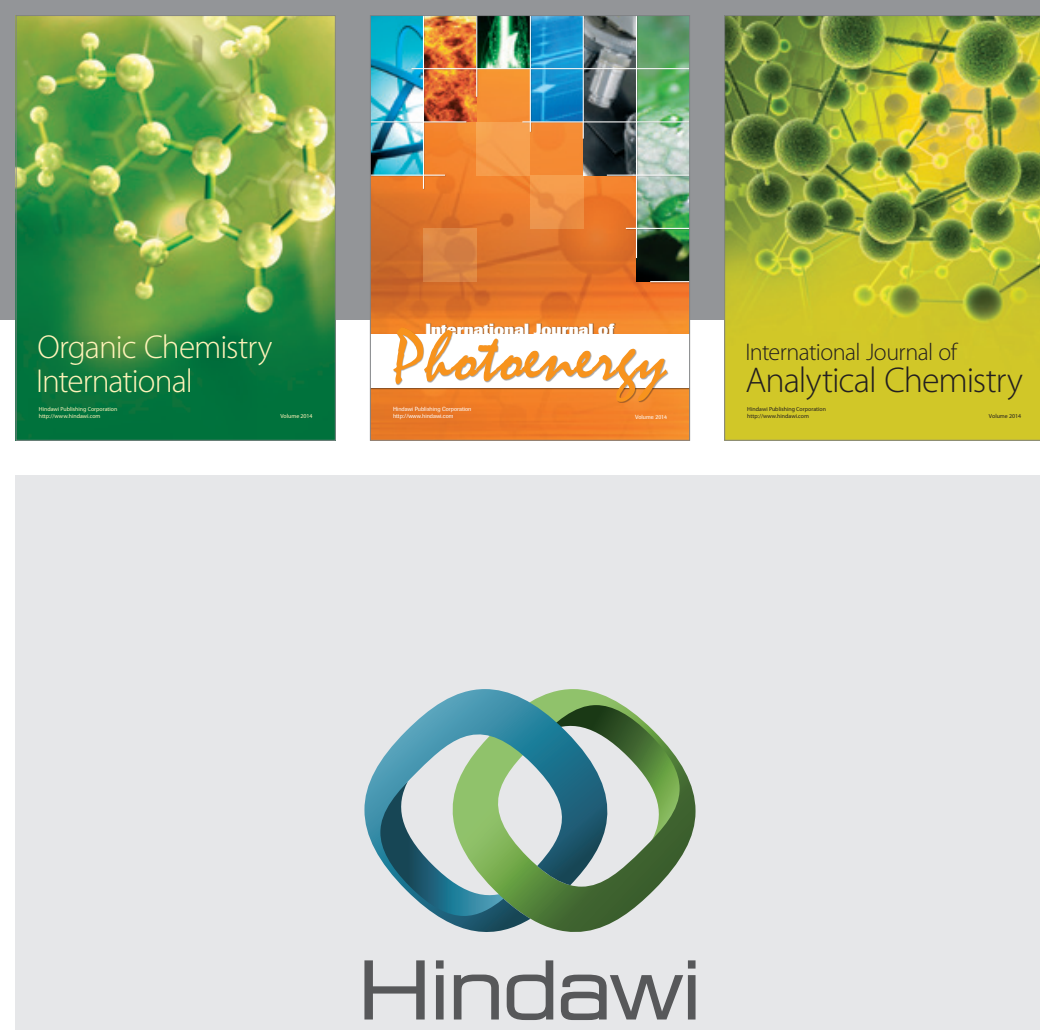

Submit your manuscripts at

http://www.hindawi.com
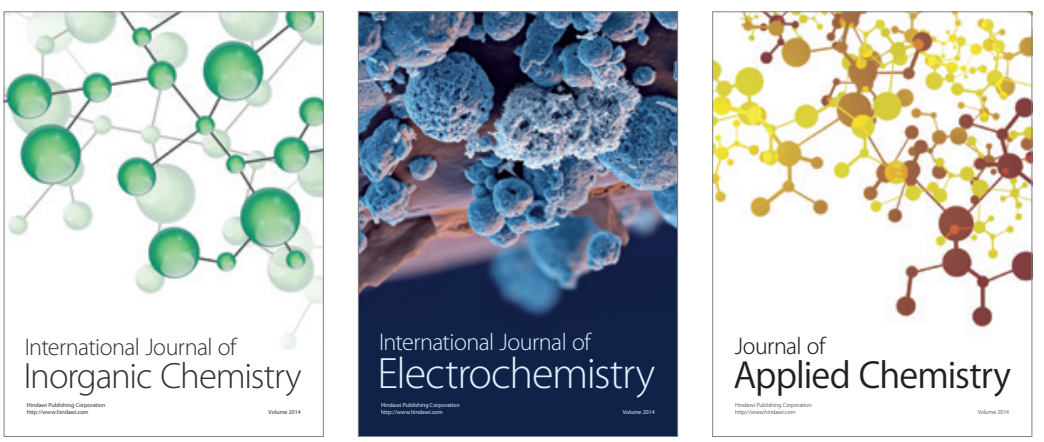

Journal of

Applied Chemistry
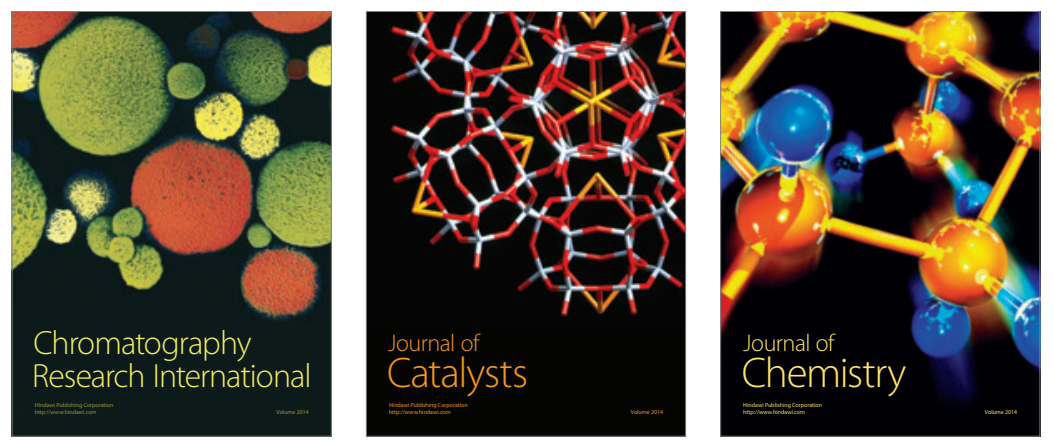
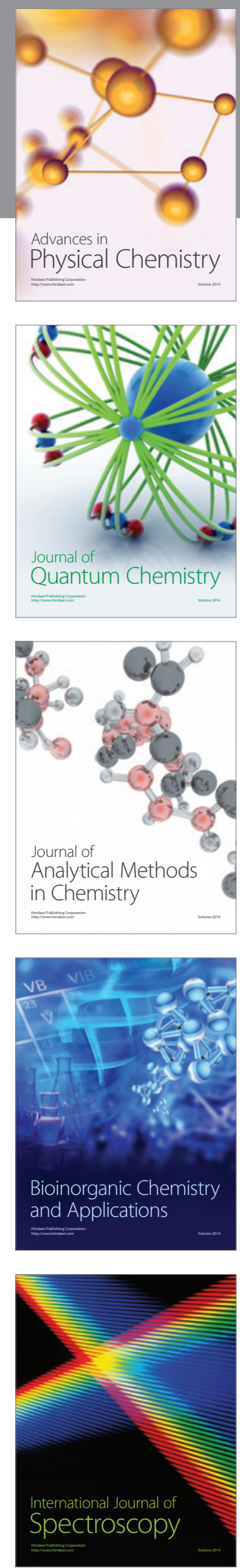